\title{
MODEL INDUKTIF: SEBUAH TAWARAN DALAM MENGAJARKAN STRUKTUR KALIMAT
}

\author{
Agus Hamdani \\ STKIP Garut \\ gushamdan69@yahoo.com
}

\begin{abstract}
This article contains ideas to present examples of inductive modeling in learning sentence structure. The stages of the offered inductive model consist of the introductory stage, the data presentation stage, the stage of concept achievement, the stabilization stage, and the closure stage. Each step consists of several steps that are concretely illustrated through a learning scenario. The emphasis of this model is directed to the development of students' thinking skills in addition to the complete mastery of the contents of the lecture structure of the sentence presented. The expected instructional impact through this inductive model scenario example is to improve students' ability to master sentence concept and deepen their experience in dealing with sentence structure data. The expected impact of the comrades is to instill the habit of always thinking critically and fostering the spirit of creativity.
\end{abstract}

Keywords: Inductive model, sentence structure, learning scenario

\section{A. PENDAHULUAN}

Salah satu masalah pokok yang sering dikeluhkan banyak pihak dalam kaitan dengan kegiatan belajar-mengajar adalah masih rendahnya daya serap pembelajar. Menurut Trianto (2007:1), kenyataan ini antara lain diakibatkan oleh banyaknya pembelajaran yang diselengggarakan dan dikelola dengan melibatkan pendekatan dan metode yang bersifat konvensional dan tidak menyentuh ranah dimensi pembelajar itu sendiri, yaitu bagaimana sebenarnya belajar itu.

Perubahan paradigma pembelajaran dari yang bersifat konvensional ke yang bersifat modern sebenarnya telah dimulai sejak lama. Dalam kenyataannya, perubahan paradigma itu tidak sepenuhnya tergambar dalam praktik pembelajaran di kelas. Masih banyak pengajar yang lebih suka menerapkan model konvensional dengan alasan model tersebut hanya memerlukan persiapan yang sederhana dan tidak memerlukan media dan bahan praktik yang lengkap. Pembelajar tidak diajarkan strategi belajar yang dapat memahami bagaimana belajar, berpikir, dan memotivasi diri sendiri. Hal seperti itu kerap terjadi juga dalam perkuliahan sintaksis, khususnya pada saat membahas struktur kalimat.

Materi struktur kalimat sebagai submateri mata kuliah sintaksis bukanlah materi yang bersifat hafalan, melainkan merupakan materi yang kompleks yang memerlukan keterampilan berpikir kritis. Mengingat hal itu, dosen harus cermat dalam menentukan suatu model yang sesuai bagi pembelajaran struktur kalimat agar tercipta situasi dan kondisi kelas yang kondusif sehingga proses pembelajaran dapat berlangsung efektif, sesuai dengan tujuan yang diharapkan. Lalu, model yang bagaimana yang diperkirakan tepat untuk pembelajaran struktur kalimat?

Salah satu jenis model pembelajaran yang dirancang untuk mengembangkan keterampilan berpikir kritis adalah model induktif. Model pembelajaran ini dilandasi oleh cara manusia dalam berpikir secara induktif. Berpikir secara induktif merupakan suatu alat generalisasi dari pemikiran kita untuk kemudian dijadikan suatu pegangan umum atas kejadiaan tertentu. 
Berdasarkan uraian di atas, pada artikel ini akan dipaparkan contoh skenario model induktif dalam pembelajaran struktur kalimat. Namun, sebelumnya akan dibahas terlebih dahulu ihwal model induktif dan teori tentang kalimat. Mudah-mudahan segala hal yang dipaparkan dalam artikel ini dapat memberikan sumbangan konseptual dalam meluaskan khazanah teori pembelajaran, terutama teori yang berhubungan dengan model pembelajaran struktur kalimat Bahasa Indonesia di perguruan tinggi.

\section{B. KAJIAN LITERATUR}

1. Ihwal Model Induktif

Model pembelajaran dapat didefinisikan sebagai sebuah rancangan pengajaran yang menggambarkan proses yang akan ditempuh dalam kegiatan belajar-mengajar agar siswa mengalami perubahan prilaku secara spesifik sesuai dengan yang diharapkan. Definisi ini selaras dengan pendapat Chauhan (1979:20) bahwa "Model of teaching can be defined as an instructional design which describes the process of specifying and producing particular environmental situations which cause the students to interactin' such away that a specific change occurs in their behavior".

Jenis-jenis model pembelajaran yang telah dikembangkan para pakar cukup banyak. Salah satu di antaranya adalah model induktif. Model yang oleh Joyce et.al (2000: 14-28) digolongkan ke dalam model pemrosesan informasi ini dilandasi oleh cara manusia dalam berpikir secara induktif. Dalam cara berpikir induktif, kumpulan fakta yang berserakan dicari kesesuaian atau keterkaitannya satu sama lain kemudian diolah ke dalam bentuk konsep atau generalisasi. Secara singkat, dapat dikatakan bahwa berpikir induktif berarti berpikir dari kasus khusus menjadi kasus umum. Hal ini sesuai dengan pendapat Eggen et.al (1979:110) bahwa “... inductive thinking proceeds from the specific to the general. In inductive thinking the individual make a number of observations which are then processed in to a concept or generalization".

Menurut Eggen (1979:191), paling sedikit terdapat tiga model yang tergolong ke dalam model pembelajaran induktif. Pertama, model induktif umum. Model ini dapat diartikan sebagai suatu strategi mengajar yang menggunakan data untuk mengajarkan konsep dan generalisasi kepada pembelajar. Dalam model ini, pengajar menyajikan data, meminta pembelajar untuk mengamati data dan membuat abstraksi berdasarkan hasil pengamatannya. Pada fase implementasinya di dalam kelas, struktur model induktif umum ini terdiri atas tiga kegiatan, yaitu menyajikan ilustrasi, menutup pelajaran, dan menambah contoh (Eggen et.al, 1979: 115-122).

Kedua, model pencapaian konsep. Model ini termasuk ke dalam model induktif yang didesain untuk mengajarkan konsep. Model ini sama dengan model induktif umum dalam hal tipe berpikir yang digunakan, tetapi desainnya khusus digunakan untuk mengajarkan bentuk konten yang disebut konsep (Eggen et.al, 1979: 142-143). Menurut Joyce et.al (2000:155), struktur model pencapaian konsep terdiri atas tiga tahap, yaitu penyajian data dan pengidentifikasian konsep, pengujian pencapaian konsep, dan penganalisisan strategi berpikir.

Ketiga, model induktif Taba. Model ini dibangun atas tiga asumsi dasar yang dikemukakan oleh Hilda Taba, yaitu berpikir merupakan sesuatu yang dapat diajarkan, berpikir merupakan transaksi aktif antara individu dengan data, dan proses berpikir berkembang melalui serangkaian tahapan yang sesuai dengan suatu hukum. Berdasarkan 
ketiga asumsi itu, Taba (Joyce et.al, 2000: 131-134) mendeskripsikan tiga strategi mengajar untuk mengembangkan keterampilan berpikir induktif, yaitu pembentukan konsep, penafsiran data, dan penerapan prinsip. Dalam setiap kegiatan, guru bergerak sepanjang strategi dengan menggunakan pertanyaan-pertanyaan yang dilontarkan untuk memandu pembelajar dari tahap aktivitas yang satu ke tahap aktivitasberikutnya pada waktu yang tepat.

\section{Teori Kalimat}

Keraf (1984:141) mengemukakan bahwa kalimat adalah satu bagian ujaran yang didahului dan diikuti oleh kesenyapan sedangkan intonasinya menunjukkan bahwa bagian ujaran itu sudah lengkap. Dengan menggunakan redaksi yang berbeda, Ramlan (2001:23) mengemukakan bahwa kalimat merupakan satuan gramatik yang dibatasi oleh adanya jeda panjang disertai nada akhir turun atau naik.

Dari definisi kalimat yang dikemukakan Keraf dan Ramlan di atas, terdapat dua buah kesamaan mendasar. Pertama, kalimat merupakan satu kesatuan dari sebuah bentuk kebahasaan. Hal itu ditandai dengan munculnya ungkapan satu bagian ujaran dalam definisi dari Keraf dan satuan gramatik dalam definisi dari Ramlan. Satu kesatuan bentuk ketatabahasaan itu dalam teori linguistik modern disebut sebagai bentuk ekspresi atau unsur segmental. Kedua, kalimat itu muncul karena adanya unsur intonasi. Unsur intonasi ini terlihat pada kata kesenyapan dan intonasi dalam definisi dari Keraf serta nada dan jeda panjang dalam definisi dari Ramlan. Dalam linguistik modern, unsur intonasi ini disebut juga unsur suprasegmental. Jadi, menurut tata bahasa struktural, kehadiran sebuah kalimat harus ditandai dengan adanya dua unsur mutlak, yaitu unsur segmental dan unsur supra segmental. (Yohanes, 1991:77).

Kalimat sering terdiri atas beberapa bagian. Antara bagianbagian itu terdapat hubungan satu sama lain dan masingmasing bagian tersebut memiliki fungsi tertentu dalam kalimat itu. Fungsi unsurunsur atau bagian-bagian kalimat itu biasanya terdiri atas subjek (S), predikat $(\mathrm{P})$, objek $(\mathrm{O})$, pelengkap (Pel), dan keterangan $(\mathrm{K})$.

Kalimat dapat digolongkan ke dalam beberapa golongan. Masingmasing ahli banyak yang memiliki perbedaan dalam penggolongan kalimat ini, terutama dalam hal penggunaan nama atau istilah serta perumusan konsep untuk setiap golongan kalimat tersebut.

\section{METODOLOGI PENELITIAN}

Dalam tulisan ini, penggolongan kalimat akan ditinjau dari dua sudut tinjauan, yaitu unsurnya dan jumlah klausanya. Berdasarkan unsurnya, kalimat dapat digolongkan menjadi dua golongan, yaitu kalimat berklausa dan kalimat tak berklausa. "Kalimat yang berklausa ialah kalimat yang terdiri dari satuan yang berupa klausa" (Ramlan, 2001:23). Yang menandakan hadirnya klausa dalam konteks ini adalah adanya fungsi $\mathrm{S}$ dan $\mathrm{P}$ sebagai unsur inti klausa, baik diikuti $\mathrm{O}, \mathrm{Pel}, \mathrm{K}$, ataupun tidak. Contoh: Lembaga itu menerbitkan majalah sastra.

"Kalimat tak berklausa ialah kalimat yang tidak terdiri dari klausa" (Ramlan, 2001:25). Dalam Tata Bahasa Baku Bahasa Indonesia (Alwi et al., 2003:363), jenis kalimat ini disebut sebagai "kalimat tak lengkap" atau "kalimat minor". Unsur segmental jenis kalimat ini bisa berupa kata atau frasa. Contoh: Astagfirullah!

Berdasarkan jumlah klausanya, kalimat dapat dibagi atas kalimat tunggal dan kalimat majemuk. "Kalimat tunggal adalah kalimat yang terdiri atas satu 
klausa." (Alwi et al., 2003:338). Untuk kalimat tunggal ini, Ramlan (2001:43) menamakannya "kalimat sederhana", sedangkan Parera (1988:27) menyebutnya "kalimat eka klausa". Contoh kalimat tunggal adalah sebagai berikut: Dia telah pergi.

Kalimat majemuk adalah kalimat yang terdiri atas dua klausa atau lebih. Untuk kalimat jenis ini, Ramlan (1981:25) menamakannya "kalimat luas" dan Parera (1988:27) menyebutnya "kalimat poliklausa". Contoh: Polisi telah memberi tembakan peringatan, tetapi penjahat itu tetap tidak mau menyerah.

Kalimat majemuk dapat dibagi lagi atas kalimat majemuk setara dan kalimat majemuk bertingkat. Kalimat majemuk setara adalah kalimat majemuk yang masing-masing klausanya memiliki kedudukan setara dalam struktur konstituen kalimat. "Hubungan antara klausa-klausanya tidak menyangkut satuan yang membentuk hierarki karena klausa yang satu bukanlah konstituen dari klausa yang lain" (Alwi et al., 2001:386). Semua klausanya merupakan klausa inti. Contoh: Anda datang ke rumah saya atau saya datang ke rumah Anda.

Kalimat majemuk bertingkat adalah kalimat majemuk yang disusun dengan menggunakan cara subordinatif (Alwi et al., 2001:388). Subordinasi menggabungkan dua klausa atau lebih yang salah satu klausanya menjadi bagian dari klausa yang lain. Oleh Ramlan (2001:47) klausa yang merupakan bagian dari klausa lainnya ini dinamakan "klausa bawahan", sedangkan klausa lainnya dinamakan "klausa inti". Dalam Tata Bahasa Baku Bahasa Indonesia (Alwi et al., 2001:389) klausa bawahan ini disebut juga dengan istilah "klausa subordinatif", sedangkan untuk klausa inti disebut juga dengan istilah "klausa utama". Contoh: Ia mengakui bahwa ia jatuh cinta kepadaku.

Kalimat di atas memiliki dua klausa, yaitu klausa ia mengakui yang berkedudukan sebagai klausa inti dan klausa ia jatuh cinta kepadaku sebagai klausa bawahan. Dalam hubungan dengan klausa inti, klausa bawahan ini meduduki fungsi O karena dapat disubstitusi dengan hal itu sehingga kalimatnya dapat menjadi: Ia mengakui hal itu.

\section{HASIL DAN PEMBAHASAN}

1. Contoh Skenario Model Induktif dalam Pembelajaran Struktur Kalimat

Pada bagian ini akan diuraikan contoh penerapan model induktif dalam pembelajaran struktur kalimat. Contoh ini dirancang dengan mempertimbangkan karakteristik materi struktur kalimat dan berbagai model pembelajaran yang tergolong ke dalam kategori model induktif.

Struktur pembelajaran model induktif yang dicontohkan ini terdiri atas lima tahap. Pertama, tahap pendahuluan. Tahap ini merupakan kegiatan membuka pelajaran yang dilakukan dengan cara menjelaskan tujuan perkuliahan yang akan dilaksanakan dan menyampaikan apersepsi yang berkaitan dengan struktur kalimat. Kedua, tahap penyajian data. Tahap ini merupakan kegiatan untuk mengenalkan mahasiswa dengan data-data struktur kalimat. Pada tahap ini mahasiswa membaca, mendengarkan, dan mengamati teks yang dijadikan sumber data kalimat. Ketiga, tahap pencapaian konsep. Tahap ini meliputi kegiatan mengidentifikasi ciri-ciri kalimat, mendefinisikan konsep kalimat berdasarkan ciri yang telah diidentifikasi, menggolongkan kalimat, dan mendefinisikan jenisjenis kalimat telah digolongkan. Semua kegiatan pada tahap ini dituntun oleh pertanyaanpertanyaan yang diajukan dosen. Keempat, tahap pemantapan. Tahap ini meliputi kegiatan menganalisis data baru berdasarkan konsep-konsep kalimat yang telah dikuasai mahasiswa. Kelima, tahap penutupan. Tahap ini meliputi kegiatan membimbing 
mahasiswa untuk menyimpulkan hasil kegiatan belajar struktur kalimat dan memberi tugas terstruktur kepada mahasiswa tentang struktur kalimat.

Penekanan model ini diarahkan pada pengembangan keterampilan berpikir mahasiswa di samping penguasaan secara tuntas isi perkuliahan struktur kalimat yang disajikan. Oleh karena itu, model ini diharapkan memiliki dua dampak, yaitu dampakinstruksional dan dampak penyerta. Dampak intruksional yang diharapkan adalah meningkatkan kemampuan mahasiswa dalam menguasai konsep kalimat dan jenisjenis kalimat bahasa Indonesia. Adapun dampak penyerta yang diharapkan melalui model ini adalah menumbuhkan kebiasaan untuk selalu berpikir kritisdan menumbuhkan semangat kreativitas.

Contoh skenario pembelajaran dari kelima tahap model induktif di atas adalah sebagai berikut.

a. Tahap Pendahuluan

1) Dosen menjelaskan tujuan, materi, dan bentuk perkuliahan yang akan dilaksanakan.

Dosen : Selamat pagi!

Mudah-mudahan

Anda tetap

bersemangat

untuk mengikuti

perkuliahan

sintaksis hari ini.

Perkuliahan hari

ini bertujuan

untuk membawa

Anda agar dapat

mengidentifikasi,

merumuskan, dan

menggolongkan

jenis-jenis kalimat

dalam bahasa

Indonesia. Selama

kurang lebih dua jam Anda akan berlatih, bertanya jawab, dan berdiskusi untuk dapat memahami

dan menguasai

kalimat tersebut.

2) Dosen berusaha mendorong mahasiswa untuk mengungkapkan latar pengetahuan dan pengalaman mereka mengenai materi sintaksis yang telah mereka kuasai.

Dosen : Istilah kalimat sebenarnya bukanlah istilah yang asing di telinga Anda.

Sejak SD sampai SLTA Anda telah mengenal istilah itu. Coba Anda kemukakan. Apayang dimaksud dengan

kalimat itu? Jenis-jenis kalimat apa saja yang pernah Anda kenal? Berilah Contohnya! (Menyampaik an pertanyaan kepada semua mahasiswa lalu memberi kesempatan kepada beberapa orang untuk menjawabnya)

Mahasisw (Beberapa a: mahasiswa mengemukaka $\mathrm{n}$ pendapatnya) 
3) Dosen menjelaskan hubungan materi yang akan dipelajari dengan materi yang telah dikuasai mahasiswa.

Dosen : Bagus. Sekarang kita akan mencoba untuk memperdalam pemahaman kita tentang kalimat. Materi ini sebenarnya berhubungan sangat erat dengan materi minggu yang lalu, yaitu klausa. Bahkan nanti akan kita pelajari adanya beberapa penggolongan kalimat yang didasarkan pada ada-tidaknya klausa dan penggolongan kalimat yang didasarkan pada jumlah klausa yang terdapat di dalamnya.

Sebelum kita membahas materi kalimat ini, coba Anda baca terlebih dahulu teks yang akan saya bagikan ini.

b. Tahap Penyajian Data

1) Dosen memberi kesempatan kepada semua mahasiswa untuk membaca teks yang dibagikan. Teks:

$$
\begin{aligned}
& \text { Keluarga Mas Marta Menggala } \\
& \text { Desa tenjolaut terletak di } \\
& \text { pegunungan priangan } \\
& \text { pemandangan desa ini indah dan } \\
& \text { hawanya sejuk oleh karena itu }
\end{aligned}
$$

setiap hari minggu desa ini sering didatangi orang jika dari atas bukit melayangkan pandangan ke arah lembah desa tenjolaut orang akan melihat deretan rumah yang cukup teratur yang paling bagus di antara rumah-rumah itu adalah rumah mas marta menggala. Mantan lurah di desa tenjolaut lurah yang sekarang bernama mas saca menggala ia anak tertua dari mas marta menggala. Sejak kanak-kanak mas saca menggala sangat dimanjakan oleh ayah dan ibunya semua keinginannya selalu dituruti kedua orang tuanya hal itu dilakukan karena kedua orang tuanya telah berikrar sewaktu mereka masih miskin mereka akan memenuhi segala keinginan mas saca menggala apabila dinasibkan menjadi orang kaya karena mengetahui ikrar itu mas saca menggala kerap kali meminta sesuatu kepada orang tuanya.

2) Dosen memberi kesempatan kepada semua mahasiswa untuk mendengarkan pembacaan teks tersebut.

Dosen: Teks yang anda miliki ditulis menggunakan huruf kecil dan belum disertai dengan tanda baca. Sekarang anda dengarkan pembacaan teks tersebut, lalu penggalah teks itu menjadi beberapa satuan sesuai dengan jeda 


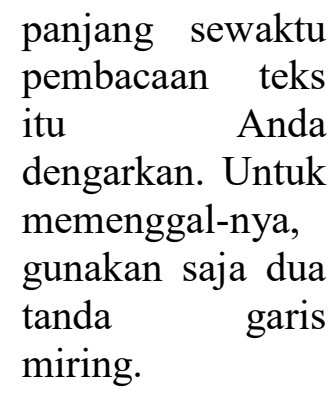

Maha- (Mendengarkan

siswa: pembacaan teks sambil membubuhkan tanda garis miring pada teks tersebut di setiap jeda panjang yang didengar)

c. Tahap Pencapaian Konsep

1) Dosen menuntun mahasiswa untuk mengidentifikasi satuansatuan bahasa yang diawali dan diakhiri jeda panjang pada paragraph pertama.

Dosen

$$
\begin{aligned}
& \text { Berapa } \\
& \text { jumlah } \\
& \text { satuan } \\
& \text { bahasa yang } \\
& \text { Anda } \\
& \text { penggal } \\
& \text { pada } \\
& \text { paragraf } \\
& \text { pertama teks } \\
& \text { tersebut? }
\end{aligned}
$$

Mahasiswa: Ada delapan.

Dosen : Coba tuliskan satu persatu! (Meminta salah seorang mahasiswa untuk menuliskann ya di papan tulis)

Mahasiswa: (1) //desa tenjolaut terletak di pegunungan priangan//
(2)

//pemandang an desa ini indah dan hawanya sejuk/l

(3) /loleh karena itu setiap hari minggu desa ini sering $d i$ datangi orang//

(4) //jika dari atas bukit melayangka $n$ pandangan ke arah lembah desa tenjolaut, orang akan melihat deretan rumah yang cukup teratur// (5) /lyang paling bagus di antara rumahrumah itu adalah rumah mas marta menggala// (6) //mantan lurah di desa tenjolaut/I

(7) I/lurah yang sekarang bernama mas saca menggalal/ (8) //ia anak tertua dari mas marta menggala// 


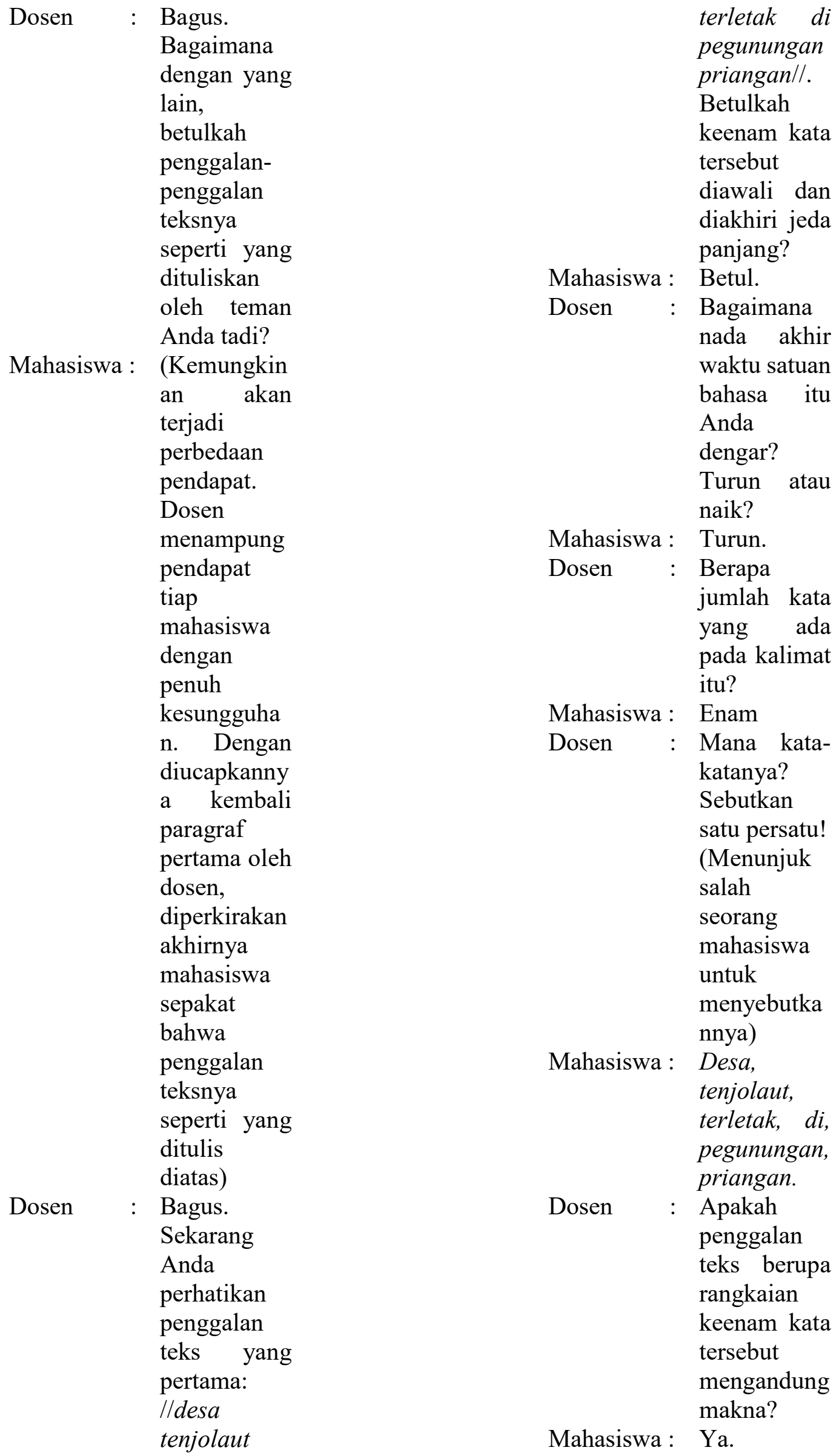




Dosen $\quad$ Bagus.
Berdasarkan
ciri-ciri yang
telah
dibicarakan
tadi, maka
penggalan
teks: //desa
tenjolaut
terletak di
pegunungan
priangan//
disebut
kalimat.
Begitupun
dengan
ketujuh
penggalan
teks
berikutnya.

2) Dosen memotivasi mahasiswa untuk merumuskan konsep kalimat.

$\begin{aligned} & \text { Dosen }: \text { Telah saya } \\ & \text { katakan tadi } \\ & \text { bahwa } \\ & / / \text { desa } \\ & \text { tenjolaut } \\ & \text { terletak di } \\ & \text { pegunungan } \\ & \text { priangan// } \\ & \text { adalah } \text { kalimat. } \\ & \text { Ciri-cirinya } \\ & \text { telah kita } \\ & \text { bahas. } \\ & \text { Berdasar- } \\ & \text { kan ciri-ciri } \\ & \text { itu, lalu apa } \\ & \text { sebenarnya } \\ & \text { yang } \\ & \text { dimaksud } \\ & \text { dengan } \\ & \text { kalimat? } \\ & \text { (Mengemuk } \\ & \text { akan } \\ & \text { pendapat- } \\ & \text { nya masing- } \\ & \text { masing. } \\ &\end{aligned}$

Dosen

memberi-

kan

kebebasan

kepada

semua

mahasiswa

untuk

mengemu-

kakan

rumusan-

nya sendiri.

Diperkiraka

n akan

terjadi

banyak

rumusan

kalimat

yang

dikemukaka

n oleh

mahasiswa.

Namun

dengan

bimbingan

dosen

diperkira-

kan

akhirnya

mereka

sepakat

bahwa

kalimat

adalah

"satuan

bahasa

bermakna

yang diawali dan diakhiri jeda panjang disertai nada akhir turun atau naik".

3) Dosen memberi kesempatan kepada mahasiswa untuk membubuhkan tanda baca pada teks tersebut.

Dosen: $\quad \begin{array}{ll}\text { Tadi Anda } \\ \text { telah dapat }\end{array}$




$\begin{array}{ll} & \text { merumuskan } \\ \text { pengertian } \\ \text { kalimat. Saya } \\ \text { yakin Anda } \\ \text { pun telah } \\ \text { mengerti } \\ \text { bagaimana } \\ \text { cara-cara } \\ \text { menuliskan } \\ \text { sebuah } \\ \text { kalimat. Oleh } \\ \text { karena itu, } \\ \text { sebelum kita } \\ \text { lanjutkan } \\ \text { pembahasan } \\ \text { tentang } \\ \text { kalimat ini, } \\ \text { alangkah } \\ \text { lebih baik } \\ \text { bila Anda } \\ \text { lengkapi dulu } \\ \text { kalimat- } \\ \text { kalimat yang } \\ \text { ada pada teks } \\ \text { tersebut } \\ \text { dengan huruf } \\ \text { yang sesuai } \\ \text { dan dengan } \\ \text { tanda baca } \\ \text { yang tepat. } \\ \text { (Membubuhk } \\ \text { an penulisan } \\ \text { huruf yang } \\ \text { sesuai dan } \\ \text { tanda baca } \\ \text { yang tepat } \\ \text { pada kalimat- } \\ \text { kalimat yang } \\ \text { ada pada teks } \\ \text { yang } \\ \text { dimilikinya) }\end{array}$

4) Dosen meminta mahasiswa untuk memperhatikan judul teks dan kalimat pertama teks tersebut yang ditayangkan melalui LCD proyektor. (Judul teks: Keluarga Mas Marta Menggala. Kalimat (1): Desa Tenjolaut terletak di pengununganPriangan)

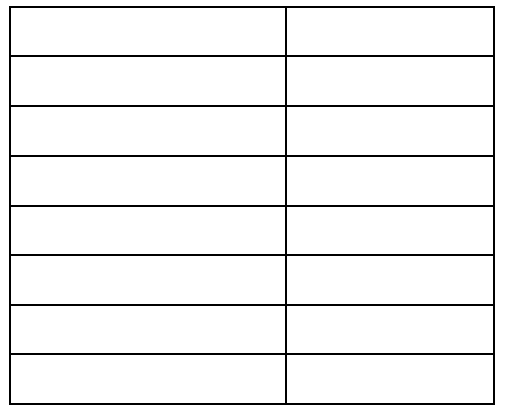

\section{E. SIMPULAN REKOMENDASI}

DAN

Materi struktur kalimat sebagai submateri mata kuliah sintaksis merupakan materi yang memerlukan keterampilan berpikir kritis. Salah satu jenis model pembelajaran yang dirancang untuk mengembangkan keterampilan berpikir kritis adalah model induktif. Model pembelajaran ini dilandasi oleh cara manusia dalam berpikir secara induktif. Dalam cara berpikir induktif, kumpulan fakta yang berserakan dicari kesesuaian atau keterkaitannya satu sama lain kemudian diolah ke dalam bentuk konsep atau generalisasi.

Contoh model induktif dalam pembelajaran struktur kalimat yang telah dipaparkan di atas bukanlah contoh mutlak dan kaku. Dalam pelaksanaannya di dalam kelas dosen dapat saja memodifikasi model tersebut sesuai dengan situasi yang dihadapi. "Sesungguhnya tidak ada satu model mengajar pun yang paling cocok untuk semua situasi ..." (Dahlan, 1990:19). Yang terpenting bila dosen akan menggunakan model induktif dalam perkuliahan sintaksis maka ia harus memahami dengan baik hakikat berpikir induktif dan dapat menerapkan model induktif untuk mendukung tercapainya tujuan pembelajaran.

Secara umum, model pembelajaran induktif memiliki ciri kegiatan pembelajaran dikembangkan mengikuti pola proses berpikir induktif, menekankan pada proses di samping 
hasil belajar yang hendak dicapai, pembelajar terlibat langsung dalam proses pembentukan konsep, penafsiran, dan penerapannya, bersifat kooperatif, artinya memberikan kesempatan kepada pembelajar seluas-luasnya untuk menuangkan segala ide dan pikirannya atau untuk mengaktualisasikan dirinya sendiri, dan pengajar lebih banyak berperan sebagai motivator dan fasilitator.

Pertimbangan utama penyusunan model pembelajaran adalah tujuan pembelajaran yang hendak dicapai. Pertimbangan lainnya adalah materi pembelajaran, tingkat perkembangan kognitif pembelajar, dan sarana atau fasilitas yang tersedia. Dengan kata lain, model pembelajaran akan berfungsi optimal jika diselaraskan dengan tujuan pembelajaran, materi pembelajaran, pembelajar, fasilitas, serta keterampilan dosen untuk menerapkan model tersebut.

\section{DAFTAR PUSTAKA}

Alwi, Hasan et al. (2003). Tata Bahasa Baku Bahasa Indonesia. Jakarta: Balai Pustaka.

Bloomfield, Leonard. (1995). Language. Terjemahan I. Sutikno. Bahasa. Jakarta: PT Gramedia Pustaka Utama.

Chauhan, S.S. (1979). Innovation in Teaching Learning Process. New Delhi: Vikas Publishing House PVT.LTD.

Dahlan, M.D. (1990). Model-Model Mengajar. Bandung: Diponegoro.

Eggen, Paul et al. (1979). Strategies for Teacher: Information Processing Models in Classroom. New Jersey: Prentice Hall Inc.

Joyce, Bruce et al. (2000). Models of Teaching. New Jersey: Prentice Hall Inc. Englewood Cliffs.

Keraf, A. Sony dan Mikhael Dua. (2001): Ilmu Pengetahuan: Sebuah Tinjauan Filosofis. Yogyakarta: Kanisius.
Keraf, Gorys. (1984). Tata Bahasa Indonesia. Ende-Flores: Nusa Indah.

Parera, Jos Daniel. (1988). Sintaksis. Jakarta: Gramedia.

Ramlan, M. (2001). Ilmu Bahasa Indonesia: Sintaksis. Yogyakarta: C.V.Karyono.

Renninger, K. Ann. (2009). Interest and Identity Development in Instruction: An Inductive Model. Dalam Journal of Research in Science Teaching. 39, 965-980. Tersedia: http//www. tandfondline.com/doi/abs. Februari 2012)

Swartzendruber, Kara. (2008). The Picture Word Inductive Model and Vocabulary Acquisition. International Journal of Educational Psychology,93(3),498-520.

Tersedia: http//soar.wichita.edu/ dspace/bitstream/handle/1005/ grasp \%20178.pdf. (23Februari 2012)

Taba, Hilda et al. (1979). A Teacher's Handbook to Elementary Social Studies: An Inductive Approach. Massachusetts: Addison-Wesley PublishingCompany.

Trianto. (2007). Model-Model Pembelajaran Inovatif Berorientasi Konstruktivistik. Jakarta: Prestasi Pustaka Publisher.

Verhaar, J.W.M. (1989). Pengantar Lingguistik. Yogyakarta: Gadjah Mada University Press.

Yohanes, Yan Sehandi. (1991). Tinjauan Kritis Teori Morfologi dan Sintaksis Bahasa Indonesia. Ende Flores: Nusa Indah. 